\title{
GESTÃO EDUCACIONAL E PROJETO POLÍTICO PEDAGÓGICO: REFLETINDO SOBRE A EDUCAÇÃO PARTICIPATIVA NA ESCOLA
}

\author{
Tatiana Pinheiro de Assis Pontes ${ }^{1}$, Mauricio Fonseca Pontes ${ }^{2}$ \\ ${ }^{1}$ Doutora em Educação pelo Programa de Pós-Graduação em Educação da Universidade Estadual Paulista - UNESP/ Presidente Prudente. \\ Professora do Departamento de Ciências da Educação - DECED da Universidade Federal de São João del-Rei -UFSJ, São João del-Rei-MG. E-mail: \\ tatiana.pinheiro2@hotmail.com \\ ${ }^{2}$ Graduado em História pela Universidade Estadual Paulista - UNESP. Professor de História junto à Secretaria Estadual de Educação de São Paulo e \\ Diretor de Escola na Secretaria Municipal de Educação, Araçatuba, SP.
}

\section{RESUMO}

Este texto, intitulado "Gestão educacional e Projeto Político Pedagógico: refletindo sobre a educação participativa na escola", apresenta reflexões/discussões sobre a relação entre a gestão educacional e a ideia de educação participativa e democrática. Para abordagem do tema, além das contribuições do referencial bibliográfico, são apresentadas análises de documentos oficiais, que normatizam e/ou orientam a organização e o desenvolvimento do trabalho escolar, entre eles, destacamos o Projeto Político Pedagógico que, neste estudo, concebemos como a própria organização do trabalho escolar. Fundamentados em Paulo Freire, defendemos a educação participativa como um dos pilares para a efetivação da democracia na gestão da escola, nessa perspectiva, torna-se essencial a implementação de mecanismos viabilizadores da gestão democrática. Portanto, este estudo tem como objetivo central refletir e lançar a discussão sobre a importante função social do Projeto Político Pedagógico escolar, pois acreditamos que esse documento pode ser um instrumento vital no desenvolvimento do projeto educativo voltado à participação popular, ao desenvolvimento da democracia na e pela educação. Trata-se de uma pesquisa qualitativa, de natureza documental e bibliográfica, de forma que os dados foram interpretados, analisados e apresentados a partir das abordagens de estudiosos da área. Entre as conclusões possíveis, concordamos com Freire sobre a necessária efetivação do modelo de gestão democrática e participativa baseada na incorporação de um método fundado na práxis dialógica, que garanta a organização do trabalho pedagógico como produto social, superando a histórica prática da gestão escolar verticalizada.

Palavras-chave: Gestão Educacional; Educação Participativa; Projeto Político Pedagógico; Gestão Democrática; Participação Popular.

\section{EDUCATIONAL MANAGEMENT AND PEDAGOGICAL POLITICAL PROJECT: REFLECTING ON PARTICIPATORY EDUCATION IN SCHOOL}

\begin{abstract}
This text, entitled "Educational Management and Political Pedagogical Project: Reflecting on Participatory Education in School", presents reflections / discussions about the relationship between educational management and the idea of participatory and democratic education. In order to approach the theme, in addition to the contributions of the bibliographic reference, some analyzes of official documents are presented, which regulate and / or guide the organization and development of school work. Among them, we highlight the Political Pedagogical Project that, in this study, we conceive as the very organization of school work. Based on Paulo Freire, we defend participatory education as one of the pillars for the implementation of democracy in school management. In this perspective, it becomes essential to implement mechanisms that enable democratic management. The main purpose of this study is to reflect and launch the discussion about the important social function of the School Political Pedagogical Project, since we believe that this document can be a vital instrument in the development of the educational project aimed at popular participation, the development of democracy in the education. It is a qualitative research, of a documentary and bibliographic nature, in such a way that the data were interpreted, analyzed and presented from the approaches of scholars in the area. Among the possible conclusions, we agree with Freire on the necessary implementation of the model of democratic and participatory management based on the incorporation of a method based on dialogical praxis, which guarantees the
\end{abstract}


organization of pedagogical work as a social product, surpassing the historical management practice school education.

Key words: Educational Management; Participative Education; Political Pedagogical Project; Democratic management; Popular participation.

\section{INTRODUÇÃO}

Abordar o tema Gestão Educacional é uma tarefa complexa em virtude, principalmente, de sua abrangência. Significa tecer considerações sobre as ações pedagógicas desenvolvidas no campo educacional, e, por conseguinte, fomentar reflexões sobre as concepções que motivam o desenvolvimento do todo o processo educativo.

Sabemos que a Educação sistematizada não é imparcial e que o desenvolvimento de um projeto de educação é permeado de intenções e de ideologias (FREIRE, 2002). Do mesmo modo, quando falamos em Gestão Educacional nos referimos à materialização de intenções e de planejamentos repletos de influências ideológicas.

No caso brasileiro, a Gestão Educacional tem fundamentação nas mais importantes leis que envolvem a educação escolar: a Constituição Federal de 1988 (CF/88) e a Lei de Diretrizes e Bases para a Educação Nacional (LDB). Com base nesses documentos podemos compreender a Gestão Educacional como a forma de planejar, organizar, normatizar, regular e executar a educação escolar pelos sistemas de ensino, que, por sua vez, são regulados pelos respectivos entes federados: nacional, estadual, municipal e distrito federal.

Sobre o significado dos termos concernentes à gestão educacional, vale organizá-los conforme o contexto a que se refere, a fim de viabilizar a melhor compreensão do leitor. Assim, apresentamos abaixo, de forma breve e à luz de alguns autores da área e de documentos oficiais, concepções sobre o termo gestão nas diversas esferas de sua abrangência no contexto educacional.

Em linhas gerais, o termo gestão é concebido por Libâneo (2008) como a atividade pela qual são mobilizados meios e procedimentos para se atingir determinados objetivos, ou seja, são "os processos intencionais e sistemáticos de se chegar a uma decisão e de fazer a decisão funcionar [...]" (LIBÂNEO, 2008, p. 101).

No contexto educacional, a gestão é concebida por Paro (2010) como o ato de administrar ou de mediar todos os recursos, mobilizando-os para a obtenção de resultados. Ainda na concepção do autor, a gestão educacional, com ênfase no papel desempenhado pelo diretor escolar, pode ser comparada à administração empresarial, que se curva muito mais aos aspectos burocráticos do que às ações de natureza diretamente pedagógicas.

No caso dos Sistemas de Ensino, com base na LDB e demais legislações educacionais, a gestão é dirigida ou administrada por órgãos (Secretarias de Educação, diretorias de ensino), que orientam, instituem normas, acompanham e avaliam 0 desenvolvimento do trabalho pedagógico nas unidades de ensino.

Além das esferas de abrangência supramencionadas, há ainda a gestão que ocorre no interior dos estabelecimentos de ensino, ou seja, feita no cotidiano de cada escola. Nesse espaço o trabalho escolar conta com a orientação e o acompanhamento de gestores escolares, tanto no âmbito administrativo como na organização do trabalho pedagógico.

Portanto, abordar o tema gestão consiste em lançar questões, discussões e declarações sobre um processo intencional, de caráter político e social. Trata-se de uma ação, que materializará o planejamento ideológico e político que a fundamenta.

Vale retomar que a partir das reformas educacionais ocorridas no Brasil após o período da ditadura civil militar, na década de 1980, o advento da CF/88 estabeleceu uma lógica de participação federativa na oferta e no desenvolvimento da educação escolar. Por meio do estabelecido regime de colaboração entre os entes federativos (sistemas: federal, estaduais, municipais e do distrito federal), iniciou-se um processo de descentralização do planejamento, do financiamento e da administração do ensino.

Anterior à promulgação da $\mathrm{CF} / 88$, os encontros, as conferências internacionais já davam sinais de grande influência sobre a educação brasileira. Essa articulação com os organismos internacionais suscitaram planos, 
programas, documentos oficiais e dispositivos legais que modificaram concepções e ações em torno do cenário educacional do país, principalmente a partir da década de 1990.

Nessa esteira, com a perspectiva de descentralização da gestão escolar, a legislação educacional passou a regulamentar a ampliação da autonomia da escola quanto à organização do processo educativo, o que culminou na elaboração de Projetos Políticos Pedagógicos (PPP) preconizados em lei. Consoante a isso, nos termos da LDB, em seu artigo 12, fica estabelecido que, entre outras atribuições, cabe aos estabelecimentos de ensino: "elaborar e executar sua proposta pedagógica, administrar seu pessoal e seus recursos materiais e financeiros, assegurar o cumprimento dos dias letivos e horas-aula estabelecidas", velar pela aprendizagem dos alunos, assegurando, inclusive formas de recuperação da aprendizagem, além de promover a articulação com a família e com a comunidade em geral.

Sobre a elaboração do PPP na escola, Libâneo, Oliveira e Toschi (2009, p.178) afirmam que o documento/ação é "[...] proposto com o objetivo de descentralizar e democratizar a tomada de decisões pedagógicas, jurídicas e organizacionais na escola, buscando maior participação dos agentes escolares".

Podemos notar que a elaboração do PPP vai ao encontro dos princípios constitucionais que agrega à educação o direito fundamental inalienável e como vistas à formação integral do aluno. Pois, ao produzirem o PPP, as unidades escolares, em consonância com os respectivos órgãos administrativos, devem garantir que sejam priorizadas as necessidades e as realidades dos alunos e da comunidade local/regional.

Nesse percurso que aponta para a consolidação da educação participativa, Freire (2003) tece advertências sobre algumas características histórico-culturais da educação escolar que precisam ser superadas. Entre elas, destacam-se: a superposição da escola à realidade escolar local/regional, a orientação excessivamente centralizadora das instituições escolares; o histórico autoritarismo e o caráter assistencialista das atividades (BEISIEGEL, 2008).

Por outro lado, para que a educação escolar cumpra o papel de formação integral, torna-se necessário o planejamento de ações educativas voltadas à educação para e pela cidadania, o que significa transformar o ambiente escolar num espaço de práticas democráticas e democratizantes. Nessa perspectiva, a produção de mecanismos e instrumentos de gestão democrática no espaço intra-escolar se torna condição sine qua non.

Considerando o exposto, salientamos neste texto a importância das reflexões e das discussões em torno da construção do PPP escolar, pois compreendemos e defendemos que esse instrumento/mecanismo de gestão educacional pode viabilizar a educação participativa, a qual concebemos como um dos pilares para a efetivação da democracia na gestão da escola.

Sendo assim, este estudo tem como objetivo central refletir e lançar a discussão sobre a importante função social do PPP escolar na organização e no desenvolvimento do projeto educativo voltado à participação popular, na perspectiva de uma educação não apenas participativa, mas, sobretudo, democrática.

\section{O Projeto Político Pedagógico como mecanismo da gestão educacional democrática}

O processo de redemocratização do Brasil na década de 1980 suscitou mudanças importantes no cenário educacional. Esse período foi marcado pela busca da abertura política, com participação popular e a organização da sociedade na luta por direitos, por gestão democrática do Estado, em prol da construção de uma sociedade mais justa e igualitária. Esse cenário favoreceu mudanças nas concepções e no planejamento de ações e políticas educacionais voltadas para a abertura à democracia.

Entre as reformas ocorridas na época, a promulgação da $\mathrm{CF} / 88$ consolidou a conquista de direitos sociais, inclusive no que se refere à democratização da educação e abriu possibilidades de ampliação da participação popular na gestão educacional e favoreceu o desenvolvimento da autonomia dos entes federados e dos sistemas de ensino. Os movimentos sociais em prol da democracia alcançaram o interior das unidades escolares, fortalecendo a implementação dos órgãos colegiados.

$\mathrm{Na}$ década seguinte, anos de 1990, a educação escolar foi pauta de muitos estudos teóricos e de agendas políticas. Nesse período, uma das ações de expressiva relevância consiste na promulgação da nova LDB/96, que, apesar de suas limitações e/ou omissões, vem garantir no texto legal a abertura da gestão educacional, 
principalmente ao estabelecer a prática da democracia no planejamento e nas decisões do trabalho escolar como um dos princípios fundamentais de desenvolvimento da educação escolar. Assim, estabeleceu-se a organização do espaço e do trabalho pedagógico escolar tendo como participantes dessa gestão pais, alunos, professores e demais educadores, com vistas à articulação efetiva entre a instituição escolar e a comunidade.

Diante dessa concepção de gestão participativa e democrática surge a necessidade de implementação de ações e de mecanismos voltados às perspectivas políticas e educacionais da gestão escolar.

Vale retomar a $\mathrm{CF} / 88$ para não perdermos de vista que o texto legal garantiu, por um lado, a autonomia aos sistemas de ensino em elaborarem as suas propostas pedagógicas e por outro lado, por meio da LDB, estabeleceu a participação dos profissionais da educação e dos pais de alunos no planejamento e no acompanhamento de seus projetos pedagógicos locais.

No desdobramento desse cenário, foram surgindo progressivamente necessidades de planejamentos e de elaboração de documentos oficiais que garantissem a consolidação das perspectivas lançadas nos projetos educacionais.

Notamos nesse contexto que os termos planejamento, plano e projetos se tornaram alvos de muitos estudos e passaram a ser comumente incorporados nos discursos relacionados aos processos de gestão educacional.

Gandin (2001) aborda a questão concernente ao planejamento e declara que podemos compreendê-lo como as ações a serem executadas com vistas às necessidades de alguém ou de grupos, tendo por base o que é socialmente desejável.

Entretanto, elucida que,

É impossível enumerar todos os tipos e níveis de planejamento necessários à atividade humana. Sobretudo porque, sendo a pessoa humana condenada, por sua racionalidade, a realizar algum tipo de planejamento, está sempre ensaiando processos de transformar suas ideias em realidade. Embora não o faça de

$$
\begin{aligned}
& \text { maneira consciente e } \\
& \text { eficaz, a pessoa humana } \\
& \text { possui uma estrutura } \\
& \text { básica que a leva a divisar } \\
& \text { o futuro, a analisar a } \\
& \text { realidade e a propor ações } \\
& \text { e atitudes para } \\
& \text { transformá-la (GANDIN, } \\
& \text { 2001, p. 85). }
\end{aligned}
$$

No que se refere ao termo projeto, Veiga (2013) esclarece que está ligado à ideia de lançar para diante, ao futuro. No caso educacional, a autora afirma que se trata de planejar o que se tem a intenção de fazer, de realizar, partindo da realidade constatada, tendo por base os recursos disponíveis e visando a alterações do futuro.

Trata-se da busca de um rumo, uma direção. É intencional e, no caso educacional, constitui-se como um compromisso definido coletivamente, a partir dos interesses reais e coletivos da população majoritária e caminha na direção da formação do cidadão para um tipo de sociedade, daí a sua dimensão política. (VEIGA, 2013).

Na dimensão pedagógica é caracterizado pela possibilidade de efetivação da intencionalidade da escola, que é a formação do cidadão participativo, responsável, compromissado, crítico e criativo. Define as ações educativas e as características necessárias às escolas de cumprirem seus propósitos e sua intencionalidade (VEIGA, 2013).

Por fim, quanto ao sentido de plano, concebemos neste texto como as formas escritas de oficialização dos planejamentos e dos projetos.

\section{Bases legais para a elaboração do Projeto Político Pedagógico}

Considerando as abordagens anteriores, é importante salientarmos a necessidade e as formas de materialização dos projetos e planejamentos voltados à gestão educacional.

Ao longo das décadas, observamos o surgimento de diversos documentos oficiais, sendo que alguns contaram com a força da lei e outros foram publicados como diretrizes e propostas aos sistemas e estabelecimentos de ensino.

Entre a gama de documentos supramencionados, destacamos alguns que permanecem em vigência no contexto atual ou que ampararam a implementação de outros. 
No âmbito federal, a definição do Plano Nacional de Educação (PNE) pela lei 10.172/01, constituiu-se em um documento com metas e ações com prazo de cumprimento de dez anos. Teve o objetivo combater 0 analfabetismo, universalizar, prioritariamente, a educação básica e garantir a qualidade do ensino e a permanência do aluno na escola, estando em conformidade como o estabelecido na Constituição Federal de 1988.

Na explanação de Gracindo (2009), a aprovação desse PNE tornou-se a base para os planos decenais das outras instâncias federativas de poder (estados e municípios), bem como para a elaboração dos planos plurianuais, que dariam suporte à realização de suas metas. Vale ressaltar que a partir do PNE, os planos estaduais e municipais passaram a ser encaminhados aos respectivos poderes legislativos, ganhando força de lei e representando as decisões da sociedade nos âmbitos regionais e locais.

Para Gracindo (2009), um dos pontos fortes do PNE se deve ao fato da apresentação quantificada e datada de suas metas, o que possibilitou a verificação de seu cumprimento. A autora ressalta que após o prazo de dez anos da promulgação do primeiro PNE, verificou-se que, apesar do amparo legal, o documento não garantiu impactos que influenciassem diretamente na concepção de políticas públicas.

Gracindo (2009) destaca o Plano de Desenvolvimento da Educação (PDE), apresentado à sociedade brasileira, em maio de 2007. Trata-se de documento constituído por 28 ações voltadas à educação básica, das quais "todas se voltam para, de alguma maneira, intervir na melhoria da qualidade do ensino e somente oito garantem, direta ou indiretamente, a ampliação do acesso e permanência dos estudantes na educação básica" (GRACINDO, p. 78). A autora enfatiza que, assim como o $\mathrm{PNE} / 2001$, o PDE não provocou impactos na realidade educacional.

$\mathrm{Na}$ atualidade, o novo PNE (2014-2024) foi definido pela lei $13.005 / 14$, representando, por um lado, o final de um processo e, de outro, o início de outro momento. Não significa que se trata de uma ruptura, mas de um marco representativo, sendo configurado pelo resultado de um longo processo de discussões com a sociedade, a partir das Conferências de Educação (Nacional, estaduais, intermunicipais e municipais) e de embates no âmbito do congresso nacional com as emendas e/ou tentativas de alterações do texto produzido a partir das aspirações sociais. Contudo, a sua aprovação marcou o início de um novo momento para o cumprimento das metas projetadas para uma década (MILITÃO; PERBONI, 2017).

Vale retomar que, assim como mencionou Gracindo (2009) sobre o primeiro PNE, o novo plano resultou na reelaboração dos planos educacionais dos estados e municípios.

Outro documento de importância na orientação da educação escolar se trata das Diretrizes Curriculares Nacionais para a Educação Básica (DCNs), criadas pelo Conselho Nacional de Educação com o propósito de articularem os princípios, os critérios e os procedimentos a serem observados nos sistemas de ensino e nas unidades escolares com vistas aos objetivos da educação básica para o ensino da etapa escolar obrigatória, que compreende os alunos de 4 a 17 anos de idade. Tal documento visa orientar os estabelecimentos de ensino na elaboração de seus PPP, tendo como foco a garantia do acesso, da permanência e da aprendizagem almejada dos alunos em prol da oferta da educação de qualidade.

Mais recentemente, foi criada a Base Nacional Comum Curricular (BNCC), definindo as habilidades necessárias à aprendizagem dos alunos, visando o cumprimento dos princípios da igualdade, estabelecidos na CF-88 e na LDB e buscando legitimar a unidade e a qualidade da ação pedagógica na diversidade do país (BRASIL, 2017).

Diante disso, o documento define um conjunto de conteúdos curriculares básicos, que devem estar articulados com as diversas dimensões da vida social/cidadã. E por isso, abrange conteúdos complementares, definidos pelos sistemas de ensino e pelas unidades escolares, conforme as características regionais e locais (BRASIL, 2017).

Assim como os documentos citados anteriormente, a BNCC fundamenta a elaboração dos PPP institucionais e escolares.

A primeira versão da BNCC foi apresentada à sociedade entre outubro de 2015 e março de 2016. Em 2016 a segunda versão da BNCC foi publicada, após passar por discussões entre as Secretarias Estaduais de Educação e redes de educação de todo país. Esse processo foi coordenado pelo Conselho Nacional de Secretários de Educação (Consed) e pela União Nacional dos Dirigentes Municipais de Educação (Undime). Em 2017, a segunda versão da BNCC 
passou por revisões e foi complementada, o que deu corpo à terceira versão, disponibilizada para consulta pública no site do Ministério da Educação (MEC) ${ }^{1}$.

Vale ser destacada que o documento oficial da BNCC afirma que a segunda versão foi examinada por especialistas do Brasil e de outros países e que, em distintos momentos, a terceira versão passou por análises de leitores críticos, como especialistas, associações científicas e professores universitários, sendo que esses emitiram pareceres referentes às especificidades das etapas da Educação Básica.

Destacamos que, conforme o PNE, O levantamento da realidade, bem como as ações planejadas e implementadas para o alcance das metas e dos objetivos presentes nos documentos oficiais, como as DCNs e a BNCC, são responsabilidades dos estados, dos municípios, das instituições de ensino e de educadores de todos os segmentos do país.

Dentro dessa perspectiva, a $\mathrm{CF} / 88$ estabelece que cada um dos entes federativos, usando da autonomia conferida pela lei, elabore e implemente ações e políticas que atendam as necessidades educacionais locais e regionais, bem como garantam a articulação com os interesses públicos de todo o país. Por isso, os documentos oficiais elaborados pelos sistemas de ensino estaduais e municipais devem estar em conformidade os da esfera federal.

Notamos que os documentos citados acima visam, em tese, contribuir para a construção de uma educação de melhor qualidade, considerando as características e peculiaridades de cada região e localidade do país, tendo como foco a garantia das aprendizagens fundamentais à formação humana dos alunos.

\section{Conceitos e considerações sobre o Projeto Político e Pedagógico escolar}

Os documentos oficiais mencionados na seção anterior buscam orientar a elaboração dos documentos-base que representam os planos e projetos pedagógicos dos sistemas de ensino e das escolas. Assim, com amparo da LDB e de resoluções específicas, cada sistema de ensino regulamenta os seus regimentos e/ou estatutos

\footnotetext{
${ }^{1}$ Para aprofundamento sobre o assunto, sugerimos a consulta da BNCC disponibilizada na íntegra no site do MEC, por meio do endereço eletrônico: http://basenacionalcomum.mec.gov.br/images/BNCCpublicacao.pdf . Acesso em 02/11/2017.
}

para estabelecerem as diretrizes e as orientações administrativas e pedagógicas concernentes à organização do trabalho educacional.

Da mesma forma, as unidades escolares elaboram os seus regimentos internos, representados pelas suas diretrizes, suas orientações e suas normas específicas. Entretanto, vale lembrarmos que esses documentos, ou seja, suas normatizações devem estar alinhadas com as legislações vigentes. Ou seja, a escola possui uma autonomia relativa para elaborar os seus documentos-base internos.

Entre os documentos elaborados pelas unidades de ensino, destacamos dos, que podem ser considerados peças centrais no desenvolvimento da gestão educacional, o regimento escolar e o PPP.

Com base na legislação educacional, podemos caracterizar o regimento escolar como em um instrumento em que se estabelecem as diretrizes administrativas e as orientações para a vida escolar. Ele estabelece as normas a serem seguidas, velando pela materialização dos direitos e dos deveres de todos que convivem no ambiente escolar. Esse documento deve ser produzido mediante reflexões e diálogos entre a comunidade escolar, já que vislumbra a melhor convivência entre todas as partes envolvidas.

$O$ outro documento escrito que representa a vida da escola é o PPP escolar, que se trata de um mecanismo oficializado que, em tese, representa e apresenta a realidade e as necessidades da escola. O seu conteúdo deve ser conhecido, bem como revisitado permanentemente pela comunidade escolar (VEIGA, 2013). PPP e regimento escolar devem ser produzidos em conformidade um com o outro e com as legislações vigentes.

Ainda sobre o PPP, deve ser um documento revelador da identidade da escola, deve projetar ações e refletir os fundamentos da organização do trabalho escolar, bem como a sua realidade.

Nas palavras de Veiga (2013),

[...] o projeto políticopedagógico tem a ver com a organização do trabalho em dois níveis: como organização da escola como um todo e como organização da sala de aula, incluindo a sua relação como o contexto social imediato, procurando preservar a 
visão de totalidade. Nesta caminhada será importante ressaltar que o projeto políticopedagógico busca a organização do trabalho pedagógico da escola na sua globalidade (VEIGA, 2013, p 14).

Reiterando as palavras acima, o PPP deve ser concebido como $o$ instrumento de organização do trabalho escolar na micro e na macro dimensão. Deve ser fundado em princípios que garantam os direitos e os deveres de sua comunidade e, portanto, precisa ser um produto social e estar fundado nos princípios constitucionais da escola pública e gratuita. Sobre esses princípios, destacamos:

a) "Igualdade de condições para acesso e permanência na escola" (VEIGA, 2013, p. 16). Isso significa que, entre outras coisas, é importante expandir a oferta, mas simultaneamente garantir e manter a qualidade do ensino a todos os alunos.

b) "Qualidade, que não pode ser privilégio de minorias econômicas e sociais. $\mathrm{O}$ desafio que se coloca ao projeto políticopedagógico da escola é o de propiciar uma qualidade para todos" (VEIGA, 2013, p. 16). Para isso, deve garantir a articulação das dimensões formal/técnica e política.

c) Gestão democrática, que na educação é um princípio definido pela Constituição Federal de 1988. É caracterizada pela participação popular nos processos decisórios da instituição e na organização do trabalho pedagógico, rompendo com centralização do poder e dando transparência às ações empreendidas (VEIGA, 2013).

d) Liberdade: esse é outro princípio constitucional. Está relacionado à ideia da autonomia, que significa a possibilidade de organização do trabalho escolar conforme as especificidades de cada unidade de ensino (VEIGA, 2013).

e) Valorização do magistério: esse é um dos princípios centrais a serem discutidos no PPP, afinal, os padrões de qualidade do ensino estão diretamente relacionados à formação profissional, às condições de trabalho e a remuneração (VEIGA, 2013).
Este trabalho tem a principal intenção de analisar a relação entre a gestão educacional na escola e o desenvolvimento do PPP como mecanismo da organização do trabalho educativo voltado à perspectiva da democracia na e pela a escola.

Diante disso, cabe salientar que o objeto principal das análises aqui empreendidas consiste num instrumento cujas dimensões são, de um lado, de natureza documental e, do outro, se caracteriza pela materialização do conteúdo sistematizado no referido documento. Isso significa que, quando discutimos sobre PPP, estamos tratando ao mesmo tempo de um objeto documental e da concretização das intenções, objetivos, perspectivas e expectativas desse objeto, que por sua vez, representa uma realidade, neste caso, a organização do trabalho escolar.

Com vistas ao nosso objetivo, esta pesquisa foi desenvolvida a partir de um estudo bibliográfico e documental, possibilitando a interpretação e a análise qualitativa dos dados levantados. Cabe frisarmos que os documentos analisados apontam para a autonomia da escola no que se refere à construção de mecanismos viabilizadores da gestão democrática no cotidiano escolar. Esse dado vai ao encontro dos apontamentos lançados no referencial teórico assumido.

Quanto aos procedimentos metodológicos aqui empregados, foram realizadas buscas na literatura quanto a estudos de autores que abordam os eixos temáticos apresentados e realizadas consultas e análises de legislações e documentos oficiais que normatizam e/ou orientam sobre o conteúdo em questão. Entre os referidos documentos, citamos: Constituição Federal de 1988, Lei de Diretrizes e Bases para a Educação Nacional (LDB), Plano Nacional de Educação (PNE), Plano de Desenvolvimento da Educação (PDE), Base Nacional Comum Curricular (BNCC).

\section{RESULTADOS}

Neste estudo, concebemos o PPP como a própria organização do trabalho escolar, tanto no que se refere à organização do espaço pedagógico da instituição e das diretrizes voltadas ao ensino, à organização do trabalho pedagógico em sala de aula e à interação entre a comunidade escolar na perspectiva de corresponsabilidade do projeto educativo.

\section{MÉTODOS}


Sobre a construção do PPP na escola, ressalta-se que deve ser pautada nos princípios de igualdade, qualidade, liberdade, gestão democrática e valorização do magistério. Visa à concretização de um novo jeito de promover a gestão, partindo da reflexão coletiva sobre os princípios supracitados e projetando ações voltadas às necessidades locais.

Ainda sobre a sua construção, alguns elementos básicos devem contemplados: as finalidades da escola, a estrutura organizacional, o currículo, o tempo escolar, o processo de decisão, as relações de trabalho, a avaliação. Contudo, a escola deve assumir a tarefa fundamental de refletir sobre os seus objetivos e sobre o seu papel na formação humana, política e social (FREIRE, 2006; VEIGA, 2013).

Por se constituir em um processo democrático de decisões na gestão educacional, algumas ações são indispensáveis na elaboração do referido documento. Em consonância com Vasconcellos (2013), destacamos algumas que consideramos vitais para a sua construção:

- Reuniões pedagógicas com a equipe escolar, onde a escuta e o registro do parecer de todos os segmentos do conjunto de profissionais devem ser considerados.

Implementação dos órgãos colegiados, partindo da discussão de sua finalidade e do estudo de como viabilizá-los.

- Reuniões pedagógicas ou conferências abertas a toda comunidade escolar, refletindo e discutindo sobre a questão da responsabilidade de cada e do coletivo no desenvolvimento da gestão do trabalho educativo.

- Ações e atividades pedagógicas que envolvam a comunidade, salientando sobre a responsabilidade para com o projeto escolar.

A relação entre a construção do PPP e a gestão educacional passa pela autonomia da escola quanto ao delineamento de sua identidade. A relação de poder e com o poder da liderança é algo imprescindível. Cabe a orientação Freire (2006) quando salienta que na gestão educacional o poder conferido ao gestor líder deve ser utilizado em favor do bem social e jamais para impor as suas próprias "verdades".

Ressaltamos ainda que é de suma importância que a construção do PPP passe pela avaliação do trabalho escolar e após a sua elaboração seja acompanhado e avaliado continuamente, garantindo, assim, a sua dimensão de controle social (VEIGA, 2013).
Observamos que a escola sempre foi um espaço social marcado, por um lado, por inúmeras contradições, que dão forma às relações opressor/oprimido, controlador/controlado, administrado/administrados e por outro lado pela luta de uns e acomodação de outros (FREIRE, 1987).

Em oposição às contradições supramencionadas defendemos neste estudo a importância do PPP escolar como articulador do modelo de gestão educacional pautado na democracia.

Entendemos que a educação escolar abrange possiblidades plurais de lançar sua comunidade à evolução do pensamento ingênuo para o patamar da consciência crítica. Isso implica possibilitar o conhecimento (lúcido e crítico) da importância do seu papel na organização do trabalho pedagógico, de tal forma que cada um assuma as responsabilidades quanto à ingerência da escola (FREIRE, 2016).

Neves (2005) enfatiza que a nova pedagogia da hegemonia, que busca educar o consenso da sociedade, por meio da assunção de responsabilidades do Estado, tem velado a histórica ingenuidade das camadas populares no que se refere aos processos decisórios da gestão educacional. $O$ progressivo incentivo ao trabalho voluntário nas últimas décadas, o fortalecimento das parcerias do Estado com o terceiro setor, destacando-se as Organizações Não Governamentais - ONGS - voltadas, muitas vezes, a projetos assistenciais - tem resultado na impressão de participação efetiva da sociedade na gestão das políticas educacionais, pois, de certa forma, a participação existe, porém é, na maioria das vezes, restrita ao plano da execução e não da construção/elaboração coletiva.

Em oposição ao modelo de gestão acima, concordamos com Freire (2006) na defesa de outro jeito de gerir o trabalho pedagógico escolar, que é através da participação consciente, crítica e reflexiva do público em questão, que busca melhorias em seu projeto educativo, a partir de interesses coletivos, especialmente de sua comunidade.

Para a efetivação do modelo de gestão democrática e participativa defendida neste artigo, torna-se essencial a incorporação de um método fundado na práxis dialógica, que busca reduzir a fragmentação na divisão das tarefas e do controle hierárquico, propondo a reflexão e o diálogo sobre as necessidades do coletivo 
escolar. Nessa direção, o PPP deve ser um instrumento pautado nos objetivos e na luta de todas/os e produzido nos anseios e responsabilidades de todas/as.

Em termos de conclusão, a gestão da escola não pode mais ser dirigida de cima para baixo e, tampouco, ser ditada por normas institucionais descoladas da realidade local. Em oposição a isso deve ser feita de uma forma mais humana, democrática, que garanta à organização do trabalho pedagógico 0 seu caráter essencialmente social, ou seja, que consolide o projeto educativo como um produto social (FREIRE, 2003).

\section{REFERÊNCIAS}

BEISIEGEL, C. R. Política e educação popular: a teoria e a prática de Paulo Freire no Brasil. 4. ed. Brasília: Liber Livro, 2008.

BRASIL. Constituição (1988). Constituição da República Federativa do Brasil. Brasília: Senado Federal, 1988.

BRASIL. Congresso Nacional. Lei № 9.394 de 20 de dezembro de 1996. Estabelece as diretrizes e bases da educação nacional. Diário Oficial da União, Brasília, DF, 23 dez. 1996. Disponível em: http://www.planalto.gov.br/Ccivil 03/leis/L9394. htm Acesso em: 03 nov. 2017.

BRASIL. Ministério da Educação. Base Nacional Comum Curricular. Proposta preliminar. Terceira versão revista. Brasília: MEC, 2017. Disponível em:

http://basenacionalcomum.mec.gov.br/images/B NCCpublicacao.pdf Acesso em: 03 nov. 2017.

DOURADO, L. F. (Org.). Políticas e gestão da educação no Brasil: novos marcos regulatórios? São Paulo: Xamã, 2009.

GANDIN, D. Planejamento como uma prática educativa. São Paulo: Loyola, 2001.

GRACINDO, R. V. Plano Nacional de Educação (PNE) e Plano de Desenvolvimento da Educação (PDE): limites e perspectivas. In: DOURADO, L. F. (Org.). Políticas e gestão da educação no Brasil: novos marcos regulatórios? São Paulo: Xamã, 2009.
FREIRE, P. Pedagogia do oprimido. 17. ed. Rio de Janeiro: Paze Terra, 1987.

FREIRE, P. Pedagogia da autonomia: saberes necessários à prática educativa. São Paulo: Paz e Terra, 2002.

FREIRE, P. Educação e atualidade brasileira. 3 . ed. São Paulo: Cortez: Instituto Paulo Freire, 2003.

FREIRE, P. A educação na cidade. São Paulo: Cortez, 2006.

FREIRE, P. Conscientização. São Paulo: Cortez, 2016.

LIBÂNEO, J. C.. Organização e gestão da escola: teoria e prática. 5. ed. rev. amp. Goiânia: MF Livros, 2008.

LIBÂNEO, J. C.; OLIVEIRA, J. F.; TOSCHI, M. S. Educação Escolar: políticas, estrutura e organização. 7. ed. São Paulo: Cortez, 2009.

MILITÃO, A. N.; PERBONI, F. (Orgs.). Plano Nacional de Educação: diversos olhares. Curitiba, CRV, 2017.

NEVES, L. M. W. (Org.). A nova pedagogia da hegemonia: estratégias do capital para educar o consenso. São Paulo: Xamã, 2005.

PARO, V. H. Administração escolar: introdução crítica. São Paulo: Cortez: Autores Associados, 2010.

VASCONCELLOS, C. S. Coordenação do trabalho pedagógico - do projeto político pedagógico ao cotidiano da sala de aula. 4. ed. São Paulo. Editora Libertad, 2013.

VEIGA, I. P. A (Org.). Projeto político-pedagógico da escola: uma construção possível. 29. ed. Campinas, SP: Papirus, 2013.

Recebido para publicação em: 05/11/2017

Revisado em: 30/01/2018

Aceito em: 09/03/2018 